\title{
Quality Assessment of Microbial Inoculants as Biofertilizer
}

\author{
B. K. Mishra* and S. K. Barolia \\ ICAR-National Research Centre on Seed Spice Tabiji, Ajmer (Rajasthan), India \\ *Corresponding author
}

\section{A B S T R A C T}

\section{Keywords}

Bacillus subtilis NRCSS-1,

Biotechnology, Bioformulation, Phosphorous,

Biofertilizer, Quality standards

Article Info

Accepted:

26 September 2020 Available Online: 10 October 2020
Biofertilizer is immobile, an unclear term. It can simply be established that biofertilizers are identified as plant extracts, composted municipal waste, and various microbial mixtures with unidentified components and chemical fertilizer formulations supplemented with organic compounds. Likewise, the scientific literature has a very open interpretation of the term biofertilizer, on behalf of everything from fertilizers to plant extracts. However, biofertilizer is more commonly indicated for the use of soil microorganisms to increase the availability and absorption of mineral nutrients by plants. Therefore, it is essential to define the term "biofertilizer". There is a scheme that defines a "biofertilizer" as a substance that contains living microorganisms that colonize the rhizosphere or the interior of the plant and promote growth by increasing the supply or availability of primary nutrients and / or growth stimuli for the target crop, when applied to seeds, plant surfaces or soil. If the existence of a microorganism increases plant growth by making nutrients more available or by replacing nutrients in the soil or by increasing the plant's access to nutrients, provided that the nutritional status of the plant has been improved. Plant For microorganisms, the material that is applied to the plant or soil that contains the microorganisms, can be characterized as biofertilizer. This definition separates biofertilizer from organic fertilizer that contains organic matter. Rhizobacterial isolates Bacillus aerophilus (King's B-15/ Cor-20) was found effective for enhancing the coriander plant growth attributes as well as seed yield. There was significant effect of PGPR treatment on coriander crop yield and highest yield was found with Bacillus aerophilus $(1374.5 \mathrm{~kg} / \mathrm{ha})$ and lowest yield was observed with control.

\section{Introduction}

Prospects Phosphate solubilizing microorganisms play an important role in plant nutrition through the increase in $\mathrm{P}$ uptake by the plant, and also plant growth promoting microbes are an important contributor to biofertilization of agricultural crops. Apart from fertilization, microbial Pmobilization would be the only possible way to increase available phosphate for plant. Accordingly, great attention should be paid to studies and application of new combinations of phosphate solubilizing bacteria and other plant growth promoting rhizomicrobes for improved results as mentioned early. Concerns about the possible health and environmental consequences of using increasing amounts of mineral fertilizers and chemical pesticides have let to strong interest 
in alternative strategies to ensure yields and protection of crops. Use of microbial inoculants for biofertilizer in agriculture represents an attractive environmentally friendly alternative (A. K. and Chandra, 2012). This new approach to farming often referred to as sustainable agriculture (Manashi et al., 2017). Microbial function recently suggested as Biofertilizer: Numerous species of soil bacteria that thrive in the rhizosphere of plants, but that can grow in or around plant tissues, stimulate plant growth. These bacteria are collectively known as plant growth promoting rhizobacteria (PGPR). Some rhizobacteria that promote plant growth appear to support growth by acting as biofertilizers and biopesticides (Vessey, 2003. Plant and soil).

Evaluation of the quality of inoculants has been of interest for years. When examining peat-based rhizobia inoculants for moisture, vital counts, contaminants, and efficiency using plate counts and MPN, rhizobia counts were found to be variable, but contaminants were present in most inoculants, even more high to the number of rhizobia and affecting the efficiency of the inoculation (Yadav, 1985).

More recent studies report relatively alarming results on rhizobia inoculants, but also on products containing PSB or free N2-fixing bacteria. Furthermore, among the isolated contaminants, many strains have been found to be opportunistic pathogens for humans, plants or insects. Evaluation of the quality of AMF inoculants showed that they generally contain a very low number of viable propagules and little (or no) potential for host infection and colonization, resulting in a highly contradictory presentation in field circumstances.

In this esteem many technical difficulties associated to a large-scale production of inoculants must be snowed under. For example, media and growth conditions (temperature, $\mathrm{pH}$, time) for bacteria must be optimal in order to ensure that the cells are in good physiological conditions. For AMF, hosts might be chosen on the basis of strainhost specificity providing possibilities of AMF strain (s) to multiply. The type of cultivation and the corresponding required space are the major disadvantages for largescale production of AMF. In all cases, the provision of competent and well trained operators is of critical significance, thus assuring implementation of the right methodologies. Other important factors are minimization of the production cost and preservation of the pure microbial culture throughout the process. In this way better quality of the product is ensured (NCOF (2011) Annual Report 2010-11).

Other important step in quality provision of biofertilizers is the formulation. New carriers are needed to overcome the limitations of peat (availability, environmental impact, toxicity) and provide a more suitable environment for the microorganisms. They should maintain microbial viability and fitness during storage, as well as on seed and in soil after inoculation (Chandra, 2011).

One of the critical stages in biofertilizer production is the inoculation of the carrier. It has been broadly perceived that the utilization of a sterile carrier offers a few favorable futures over nonsterile ones. These are higher populations of the target strain (s) and a longer shelf life (Yadav et al., 2015). Moreover, contaminating microorganisms are generally able to grow faster than the target ones (especially in the case of rhizobia), therefore easily replacing them in a short period of time. They participate for space and nutrients and may also produce toxic compounds reducing the growth of other cells, or be pathogenic for plants, humans, or 
environment. Sterility is generally obtained by using a steam (autoclaving) or gamma irradiation. The last one is considered as slightly better to steam sterilization but is more expensive and slow, requiring specific costly and not easily available equipment. Other technologies such as electron acceleration have also been developed, but they are economically unjustified as well.

Another important aspect to ensure superiority is to maintain cell viability during transport and storage. It is influenced by many factors. Moisture is of utmost importance for peat products and generally reaches $45-60 \%$ by wet weight. For granular inoculants, the drying speed turned out to be of great importance. Slow drying affects cells less than fast drying. The addition of substances that provide greater tolerance to drying (such as osmoprotectants) could allow the production of additional biofertilizers resistant to severe storage conditions. Low temperatures $\left(4^{\circ} \mathrm{C}\right)$ are generally recommended as the best storage conditions. However, it has been shown that temperatures during storage and transport can be higher than $26^{\circ} \mathrm{C}$ and sometimes even $40^{\circ} \mathrm{C}$. These conditions are detrimental to rhizobia strains. It is very important to note that the effects of water content, elevated temperature and time are not mutually exclusive. Several studies have reported that microbial populations in inoculants decrease over time, resulting in lower inoculation efficiency and an increase in contaminating strains. This is especially true for products that have not been stored in optimal conditions. Generally, the expiration date for inoculants is approximately 12 months after manufacture, but some products are likely to be older when used.

Another problem encountered is that most of the literary reports evaluating the quality of biofertilizers (or the selection of strains) are carried out under controlled conditions but not in the field. Available studies have generally reported variable performance (even of very promising products under controlled conditions) due to communications between the target plant, microorganisms, soil, and environmental conditions. Other factors such as the mode of application (seed coating, application of the seed to the site or inoculation of the soil) can also affect the efficiency of the inoculation depending on the type of crop (size and fragility of the seeds) and previous treatments of the seeds. The type and density of native populations in the soil can be the main obstacles to successful inoculation. This is due to the fact that recently introduced cells must not only survive in the new potentially harmful conditions, but must compete for protective and nutritious niches, dominating native and better adapted populations. In this regard, the success of the inoculation is related to the determination of the introduced strain, that is, its ability to establish high population levels despite the hostile environment and to live as a permanent member of the soil microflora even in its absence of its host plant (Ritika and Uptal, 2014).

These complex interactions need to be better understood as they significantly affect the efficacy of inoculants and their persistence in the soil. Until now, the variability and unpredictability of results from crop to crop, location to location, and season to season have limited the wider use of inoculants.

Successful commercialization of new inoculants principally depends on the on the cooperation between the research (to formulate the best inoculant, using the right strain for the right crop in the right conditions), the private sector (to scale up the production, establish an economically viable and sustainable market chain), and the acceptance by farmers. The need for farmers' education is great. If the end users are 
convinced of the efficacy of the biofertilizers on their crops, they will be more willing to buy and use them instead of expensive and harmful chemical fertilizers. To accomplish that, the improvement of the biofertilizer quality is a critical issue. Demonstration trials with high-quality products and regular training of the farmers for the use of inoculants would lead to a greater confidence from the farmers and a significant increase in the use of biofertilizers.

The screening for PGPR and investigation of their activities are expanding at a fast pace as endeavors are made to exploit them commercially as biofertilizers.

The most valuable activities of PGPR include fixing $\mathrm{N}_{2}$, increasing the availability of nutrients in the rhizosphere, positively influencing root growth and morphology, and promoting other beneficial plant-microbe symbiosis.

The blend of these modes of actions in PGPR is also addressed, as well as the difficulties facing the more broad usage of PGPR as biofertilizers (Sathya et al., 2017).

Two types of materials are used in agriculture, fertilizer or pesticide. It can be assumed that fertilizer is required for nourishment and pesticide for medication of plants in conventional agriculture. On the other hand, biofertilizer and/or biopesticides represent respectively both materials in sustainable or environmentally friendly system (Chang, 2009; Raja, 2013) (Figure 2).

The main sources for biofertilizer are nitrogen fixing bacteria, phosphate solubilizers, and mycorrhizae. Similar to the functional foods, like restoratives and/or adjuvant, who are required for human health care; plant growth promoting rhizobacteria may be one of the compatible substances for better crops yield (Ghosh et al., 2001).
However, several limitations exist in the use of biofertilizer for agricultural system. Primarily, the efficacy for most biofertilizer is not reliable. This is due on the scarce data available about the mechanism of action of different biofertilizer in promoting plant growth. However, research into biofertilizer is increasing, trying to manage these issues (Wollurn et al., 1987).

Moreover, different parameters should be also assessed, such as: soil type, management's practices, and weather effect on biofertilizer efficacy. Furthermore, there is a block in biofertilizer development. It is difficult to test inoculant in field as routine experiments (Duhan and Yadav, 2001), as shown in Figure 1.

\section{Properties of microbial products}

The microorganisms used for development of biofertilizers are bacteria of genera Bacillus, Pseudomonas, Lactobacillus, photosynthetic bacteria, nitrogen fixing bacteria, fungi of Trichoderma and yeast. Among the microbes, the most employed microorganism is Gram (+) endospore-forming bacteria from genus Bacillus. Usually, several species of microbes are used in microbial products with an available period of by- products of about 1 2 and/or 2 3 years (Ghosh et al., 2000).

Biofertilizers can be solid or liquid. Carriers used in solid type biofertilizers are generally

As displayed by producers, microbial products stimulate plant growth, decrease pest occurrence, stimulate composting and ameliorate the soil. However, the main effect generally is the plant growth stimulation. Nevertheless, in $40 \%$ of the commercial biofertilizers manufacturers declare presence of multiple effects.

In this respect controlling the quality of biofertilizer is one of the most important 
factors. Thus their success or failure and approval or rejection by end-user, the farmers will be assured. Principally, qualities represent the number of selected microorganism in the active form per gram or milliliter biofertilizer. Up to now quality standards are developed only for Rhizobium. Furthermore, specifications of biofertilizer differ from country to country and possibly comprise parameters like: microbial density at the time of manufacture, microbial density at the time of expiry, the expiry period, the permissible contamination, the $\mathrm{pH}$, the moisture, the microbial strain, and the carrier.

Quality has to be monitored at different production stages (during pre-culture stage, carrier selection and preparing, broth formulation, mixing of broth and culture, packaging and storage). Main quality parameters to be respected during biofertilizer production are summarized in Table 1 (Gupta et al., 2004).

\section{Quality Management}

Quality management is very important process, and must be performed repeatedly to monitor the microbial products in favor of the customers (Ghosh, 1999; 2000).

The recent strategy used for evaluating quality of biofertilizers is restricted to controlling the: density of the available microorganisms, their viability and preservation. However, it is also important to set control points that do not contain available microorganisms, but are focused on the consistency of the other compositions in the final microbial products. Also it is highly desirable that the biofertilizer demonstrates the major effects for quality management of the final biofertilizer products.

It is a crucial requirement to discriminate between the role of the available microorganisms and the supplementary compositions on the effects of the biofertilizer guaranteed by the suppliers. If the final results of the two experimental schemes (microorganisms / supplements) are the same or cannot be confirmed statistically, then the product is only an organic matter.

This means that the effects of microbial products should resulted from the activity of the guaranteed microorganisms, and the target of the substances should be presented in details as a prescription. It is important to assess precisely the functions under the given usage manifested by the end-user.

\section{General method for quality control of biofertilizer}

\section{Total count}

Total count includes viable cells and dead cells by using Petroft-Hausser counter At least 10 small squares all around the total area are counted, and not only in one large square.

\section{Precautions}

Cells have to be homogeneous.

Clumping of cells (use non-ionic detergent).

It gives total count only.

Petroft, cover slip must be properly positioned to get uniform depth.

\section{Viable count}

The number of living cells is counted by spread plate or drop plate methods. Doing spread plate by making serial dilutions from 10-1 - 10-6 or 10-7 (depend on concentration) then three replicates of 0.1 milliliter of broth from 10-6 and 10-5 are spread over the YMA + CR plates.

Plates are incubated in incubator $\left(28-30^{\circ} \mathrm{C}\right)$ or at room temperature for 7 days. Colonies of 
rhizobial cells are round, opaque and have smooth margin. They are white and do not absorb red color as well as the other bacteria.

\section{Calculation of the number of rhizobia per ml;}

No. of cells $/ \mathrm{ml}=\underline{\text { no. colonies } \mathrm{x} \text { dilution factor }}$ Vol. of inoculum

\section{Vol. of inoculum}

For example, No. of cells $/ \mathrm{ml}=\underline{32 \times 106=32 \times 107}$

0.1

\section{Peat test}

For the peat inoculant, we check these qualities:

1. $\mathrm{pH}$

2. Moisture content

3. Viable number

4. Plant infection method (MPN)

\section{pH}

Maintain neutral $\mathrm{pH}$ for the inoculant. Since peat is acidic the $\mathrm{pH}$ has to be increased with $\mathrm{CaCO} 3$.

Weigh $10 \mathrm{~g}$ of inoculant, pour $20 \mathrm{ml}$ of distilled water, mix well with glass rod, incubate at least 30 minutes, and then measure with $\mathrm{pH}$ meter.

\section{Moisture content}

The optimum moisture content of peatinoculant is between 40-50 \%. At low moisture rhizobia will die rapidly. If moisture is high, inoculant may stick to the plastic bag and, thus, not good for rhizobial growth.

\section{Viable number}

The number of viable rhizobia is counted by spread-plate method as in the broth test. It is more difficult when analyzing non-sterile peat. Colonies may sometimes be contaminated by other bacteria. The well trained staff is needed to conduct this microbiological analysis.

\section{A Plant Infection Analysis using Most Probable Number Method (MPN)}

This is an indirect method of assessing plant infection on nodulation. It is widely used when peat is not sterile. It takes more time than spread plate method (because we have to grow plants). Usually do MPN to compare the results with a spread plate method. This method is based on the assumptions that:

1. If viable rhizobia are inoculated on its specific host, nodules will develop on those roots.

2. Nodulation on that inoculated plant is a proof of the presence of infective rhizobia.

3. Absence of nodule is a proof of the absence of infective rhizobia.

4. Uninoculated plants are used as control, with absence of nodule.

\section{Estimation of MPN}

Plants within any given pouch are considered as a growth unit. Nodulation is recorded + for "nodulated growth unit" or - for absence of nodule. The actual number of nodules on each plant has no meaning on MPN count. If replications are in quad replicated, the reading may be 4, 3, 2, 1 or o units. The highest dilution should show no nodulation. Refer to table, ten-fold dilutions (Handbook for Rhizobia, Somasegaran and Hoben, 1994) the 
number of replications is indicated by " $n$ " and "s"

Signifies the number of dilution steps.

The estimated number of rhizobia per $\mathrm{g}$ is calculated by the formula:

$\mathbf{x}=\frac{\mathbf{m} \mathbf{x d}}{\mathbf{v}}$

$\mathrm{m}=$ number from MPN table A.14.6 (Vincent

1970)

$\mathrm{d}=$ lowest dilution (first unit)

$\mathrm{v}=$ volume of a aliquot inoculated

Contaminants have some effect on counting. In the presence of contaminants, count of MPN will give lower results than plate counts (Roughley, 1967).

Biofertilizers, being microbial products, provide nutrients to the soil reduce agricultural load and preserve the environment. Good soil conditions are essential to improve yields and ensure the well-being of human and / or animal health. That is why materials, such as biofertilizers, that are used to maintain good soil conditions, are treated as environmental problems. However, as mentioned above, there are still some issues to be addressed regarding the use of microbial products. More thorough quality control must be performed on behalf of clients. Taking this into account, the need to develop better production techniques and improve the microbial product management system is defined.

Although the effects of biofertilizers vary in different geographic regions due to peculiarities of climate and soil conditions, the importance of biofertilizers in conserving the environment in the 21 st century should not be ignored. At the same time, the development of various biotechnological approaches should be considered in order to increase the effects of biofertilizers With Concern For The environment.

\section{Non-symbiotic $\mathrm{N}_{2}$-fixer}

In investigate aspect, microbial growth may be represented by the amplification in cell mass, cell number or any cell ingredient. Growth of the organism could be also assessed by the utilization of nutrients or accretion of metabolic products. Growth, therefore, can be determined by different methods based on one of the following assays (Eaglesham, A.R.J. 1987). (a) cell count, directly by microscopy or by an electronic particle counter, or indirectly by colony count, (b) cell mass, directly by weighing or measurement of cell nitrogen, or indirectly by turbidity; and (c) cell activity, indirectly by relating the degree of biochemical activity to the size of the population.

The growth rate of Azospirillum is expected to have reached its maximum at 3-5 days after inoculation. The suggested counting technique in this case uses the drop-plate method. Proper aseptic procedures should be observed, otherwise contaminants may be accidentally introduced during the injection of the broth culture and during serial dilution and plating. These contaminants are also detectable on the utilized indicator media and their number should be reported together with the number of viable cells as additional measure of the quality (Manashi et al., 2017)

\section{Mycorrhiza - the arbuscular mycorrhizal fungi (AMF)}

Quality control in the formulation of AMF inoculum is essential for product uniformity, reliability and reproducibility. This is applied to the laboratory, preparation room, growth room, storage room and the greenhouses, taking care into the design, to achieve the 
most efficient control in inoculum production (Singh et al., 1999).

\section{Laboratory quality control}

Laboratory quality control is applied in respect to the production of bacterial spores. They are extracted from monospecific spore cultures in the preparation room. The spores are transported in petri dishes to the laboratory and placed in a refrigerator before examination under stereoscopic microscopes. A spore from each petri dish is described and records are prepared.

\section{Preparation room quality control}

This room has to be isolated from the greenhouse and growth room, and unsterilized soil or media samples should not be stored in it. Materials (cultures; sterilized growth media) are clearly labeled and placed in specific containers. Floor should always be clean without presence of dust. All surfaces should be clean and disinfected. Containers are surface-sterilized with $10 \%$ sodium hypochlorite.

\section{Growth room quality control}

The growth room should be temperature controlled $\left(22{ }^{\circ} \mathrm{C}\right)$. Air is exhausted to the outside and no recycling is applied. Surfaces should be painted with anti-microbial paint and sterilized periodically e.g. monthly. All samples are checked for contaminants and pathogens. Watering is done manually, avoiding cross-contamination.

\section{Storage room quality control}

All samples stored are placed in plastic bags, with proper labeling, and surface of bags should be cleaned before usage. Floors and surfaces are clened regularly, preventing generation of dust.

\section{Phosphate solubilizing bacteria (Bacillus subtilis)}

Phosphate solubilizers (PS) contain phosphate solubilizing bacteria or fungi. Commercially produced PS biofertilizers (PSB) are certified in respect to the guaranteed components such as type of strains PSB isolate from fennel rhizosphere (Bacillus subtilis NRCSS-1), microbial density, and biological activity, effective in significantly increasing plant growth attributes (root and shoot biomass) and availability of phosphorus to crop plants.. If possible the rate of phosphorus absorption of target crops is also determined. The procedure shown in Figure 4 could be used for the quality control of PSB New bacterium bacillus aerophilus (king's b-15/ cor-20) for enhancing coriander growth and yield 15 . (Haradson et al., 1991) Rhizobacterial isolates, Bacillus aerophilus (King's B-15/ Cor-20) was found effective for enhancing the coriander plant growth attributes as well as seed yield. There was significant effect of PGPR treatment on coriander crop yield and highest yield was found with Bacillus aerophilus (1374.5 kg/ha) and lowest yield was observed with control (Figure 3).

\section{General procedure for quality control of PSB}

Phosphate solubilizing microorganisms play an important role in plant nutrition through increasing the available phosphate for plant. Consequently, great attention should be paid to research and formulation of new combinations of phosphate solubilizing bacteria and other plant growth promoting rhizomicrobes for improved crop yields. To ensure product safety, efficacy, and conformity to prescribed standards, quality control and regulation of bio-fertilizers are important steps (Arora et al., 2016). 
Inoculum quality control should be done at different stages: screening and efficiency at laboratory and the greenhouse scale by researchers, formulation including choice of support, packaging, and storing at industrial scale. Each step requires expertise, and everything must be governed by standards (under regulation) unfortunately, all biofertilizer production units do not follow this procedure due to lack of technical back up.

\section{Quality standards for Rhizobium and Azotobacter}

Several quality standards have been formulated for Rhizobium and Azotobacter inoculants. (Somasegaran and Hoben, 1994). These specifications are shown in Table 2.

The variability in quality standards specified for Rhizobium in various countries are as follows Somasegaran et al., 1994) (Table 3).

Although quality control standards for biofertilizer Azospirillum and PSM has not been in force, the proposed standard specification of PSM and Azospirillum are given in Table 4.

\section{Quality control measures}

The biofertilizer evaluated for the following quality standards (Herrmann, L. and Lesueur, D. 2013):

Inoculant should be carrier based or liquid based.

The inoculant should contain minimum of $10^{8}$ viable cells of bioinoculant/g of carrier on dry weight basis when it is stored at $25-30^{\circ} \mathrm{C}$.

The inoculant should have at least 6 months shelf life from the manufacturing date in case of carrier based and 9 months in case of liquid based.
The $\mathrm{pH}$ of inoculant should be between 6.0 and 7.5 .

Inoculant should show effective nodulation/nitrogen fixed on particular crop before expiry date.

The carrier material should be in the form of powder, i.e. peat, lignite, peat soil, and humus, etc.

Inoculant should be packed in 50-75 microns low-density polythene bags.

Each package should be marked legibly to give the information about name of the product, name of microbial inoculants, activity of bioinoculant, intended crop, name and address of manufacturer, type of carriers, batch and code numbers, date of manufacture, date of expiry, net quantity meant for 0.4 hectare, and storage instructions.

It should be free from any contaminant/contamination with other microorganisms.

Phosphate Solubilizers As discussed in the definition of biofertilizer, phosphate solubilizers (PS) must contain phosphate solubilizing bacteria or fungi. Commercially produced PS biofertilizers (PSB) must be certificated with guaranteed components such as type of strains, microbial density, and biological activity. If possible the rate of phosphorus absorption of target crops is more valuable as fertilizer. It is suggested that the procedure shown in next

Calculate colonies as per unit ( $\mathrm{g}$ or $\mathrm{ml}$ ) [For example: When average number of colonies is 45 on $10-5$ series. The total colony number is $45 \times 105 / \mathrm{g}$ dry matter]. Analysis of Organic Acid

Cultivation of isolate on solution medium contained unsalable phosphate

Check the solubility on medium Transparence or clearance

Analysis of the organic acids in solution by the HPLC 
Solubilization of medium solution

Liquid chromatography of organic acids

Test of Quality Certificated

Effects of inoculant which be proposed and certificated by manufacturers - Plant growth rate, nutrient absorption of crops etc.

\section{Marketed biofertilizers in India}

The following types of microorganisms as biofertilizers are available to the farmers in
India (Motsara, M. R 1995; Ghosh, T.K. 2000). Nitrogen fixer, e.g. Rhizobium, Bradyrhizobium, Azospirillum, Azotobacter, Acetobacter, Azolla and BGA. Phosphorus solubilizer, e.g. Bacillus, Pseudomonas and Aspergillus. Phosphate mobilizer, e.g. VAmycorrhiza (VAM) like Glomus. $K$ solubilizer, e.g. Frateuria aurantia. Silicate solubilzer, e.g. Thiobacillus thiooxidans Plant growth promoting biofertilizers, e.g. Pseudomonas sp. (Muraleedharan, 2010; Mishra and Arora, 2016).

Table.1 Key quality parameters of biofertilizer

\begin{tabular}{|c|c|c|c|}
\hline Forms & Liquid $\left(\mathrm{X10}^{9} / \mathrm{ml}\right)$ & $\begin{array}{l}\text { Powder } \\
\text { (X109/g) }\end{array}$ & $\begin{array}{l}\text { Granular } \\
(\mathbf{X 1 0} / \mathrm{g})\end{array}$ \\
\hline Appearance of living target bacteria & $\begin{array}{c}\text { Without strange } \\
\text { smell }\end{array}$ & Brown or black & Brown \\
\hline Fast-growing Rhizobium & $>0.5$ & $>0.1$ & $>0.1$ \\
\hline Slow-growing Rhizobium & $>1.0$ & $>0.2$ & $>0.1$ \\
\hline $\mathbf{N}$ fixation bacteria & $>0.5$ & $>0.1$ & $>0.1$ \\
\hline Si bacteria $\mathbf{P}$ bacteria & $>1.0$ & $>0.2$ & $>0.1$ \\
\hline Organic P & $>0.5$ & $>0.1$ & $>0.1$ \\
\hline Inorganic P & $>1.5$ & $>0.3$ & $>0.2$ \\
\hline Multi-strain biofertilizer & $>1.0$ & $>0.2$ & $>0.1$ \\
\hline pH & $5.5-7.0$ & $6.0-7.5$ & $6.0-7.5$ \\
\hline Water content $(\%)$ & & $20-35$ & 10 \\
\hline $\begin{array}{l}\text { Non-target bacterial Contamination } \\
(\%)\end{array}$ & $<5$ & $<15$ & $<20$ \\
\hline
\end{tabular}

Table.2 General standards specified for Rhizobium and Azotobacter biofertilizers

\section{Parameters}

Cell no. at the time of manufacture

Cell no. at the time of expiry date

Expiry date

Permissible contamination level

pH

Strain

Carrier

Nodulation test

Nitrogen fixation

\section{Rhizobium Biofertilizer}

$10^{8} / \mathrm{g}$ carrier within 15 days of manufacture

$10^{7} / \mathrm{g}$ carrier within 15 days before expiry date

Six months from the date of manufacture

Not contamination at $10^{8}$ dilution

6.0-7.5

Should be checked serologically

Should pass through 150-212 microns IS sieve

Should be positive

Above $20 \mathrm{mg} / \mathrm{g}$ of glucose

\section{Azotobacter Biofertilizer}

$10^{7} / \mathrm{g}$ carrier within fifteen days of manufacture

$10 \%$ g carrier within fifteen days before expiry date

Six months from the date of manufacture

Not contamination at $10^{7}$ dilution

$6.5-7.5$

A. chroococcum. Nothing specific species is mentioned

Should pass through 160 microns IS sieve

-

Not less than $10 \mathrm{mg} / \mathrm{g}$ of sucrose 
Table.3 Quality standards of commercial Rhizobium culture in different countries

\begin{tabular}{|l|l|l|l|}
\hline Country & $\begin{array}{l}\text { Cells/gm of culture (total viable count } \\
\text { on Congo-red agar) }\end{array}$ & & \\
\hline & Very satisfactory & Satisfactory & Doubtful \\
\hline India & More than $10^{9}$ & $10^{7}-10^{9}$ & Less than $10^{7}$ \\
\hline Australia & - & $2 \times 10^{8}$ & $10^{6}-10^{7}$ \\
\hline U. S. A. & $10^{9}$ & - & $10^{6}-10^{7}$ \\
\hline Russia & $10^{9}$ & - & - \\
\hline
\end{tabular}

Table.4 Proposed standard specifications of PSM and Azospirillum

\begin{tabular}{|l|l|l|l|}
\hline No. & Parameter & PSM & Azospirillum \\
\hline 1. & Carrier & $>100$ micron & $>100$ micron \\
\hline 2. & Base & $\begin{array}{l}\text { Carrier (Lignite/ } \\
\text { Charcoal) }\end{array}$ & $\begin{array}{l}\text { Carrier (Lignite/ } \\
\text { Charcoal) }\end{array}$ \\
\hline 3. & Moisture & $35-40 \%$ & $35-40 \%$ \\
\hline 4. & pH & $6.5-7.5$ & $7.0-8.0$ \\
\hline 5. & Viable count at manufacture & $10^{7} / \mathrm{g}$ carrier & $10^{7} / \mathrm{g}$ carrier \\
\hline 6. & Viable count at expiry & $10^{7} / \mathrm{g}$ carrier & $10^{7} / \mathrm{g}$ carrier \\
\hline 7. & $\begin{array}{l}\text { Level of contaminant PSM and } \\
\text { Nzospirillum }\end{array}$ & No at $10^{4}$ dilution & No at $10^{4}$ dilution \\
\hline 8. & Growth in Pikovskaya medium & + ve & - \\
\hline 9. & Growth in S. S. Malate medium & - & + ve \\
\hline 10. & P Solubilization zone & $1 \mathrm{~mm}$ & - \\
\hline 13. & P Solubilization & $30-50 \%$ & - \\
\hline 14. & N-fixation & - & $15 \mathrm{mg} / \mathrm{g}$ of malic acid \\
\hline 11. & Pellicle formation & - & + ve \\
\hline 12. & Shelf life & 6 months & 6 months \\
\hline & & & \\
\hline
\end{tabular}

Fig.1 Experimental process for biofertilizer testing

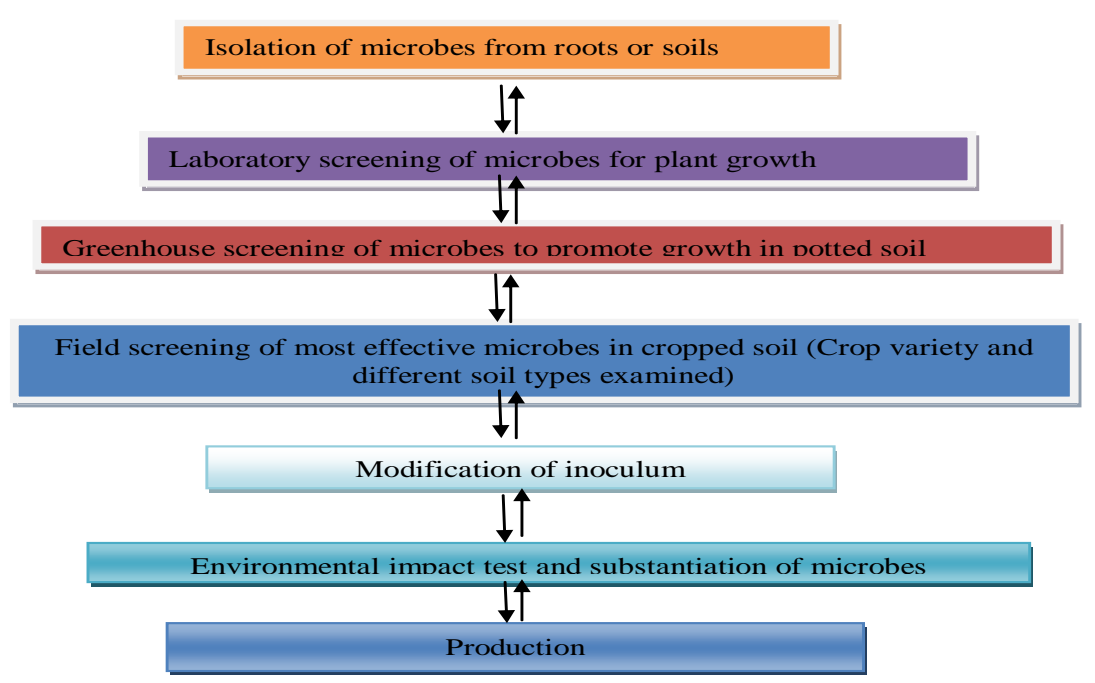


Fig.2 Procedure of biofertilizer quality control

\section{General method for quality control of biofertilizer}

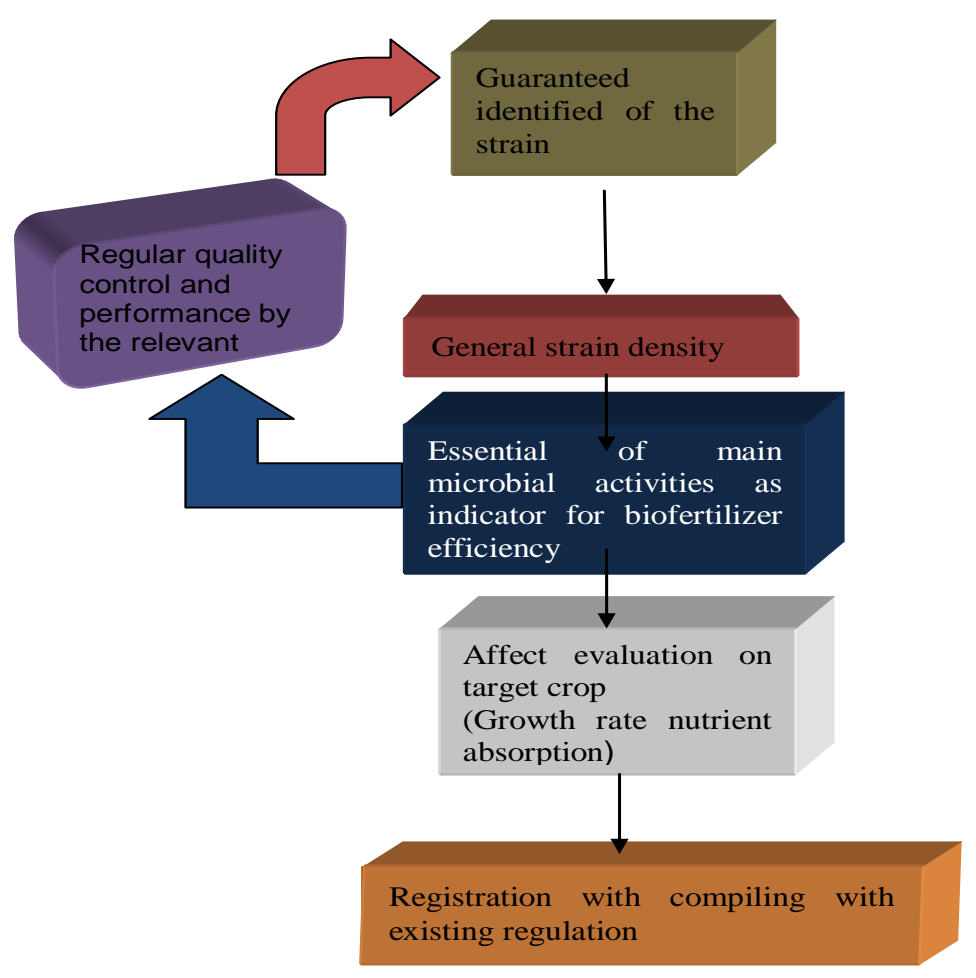

Fig.3 Procedure of biofertilizer quality control of PSB
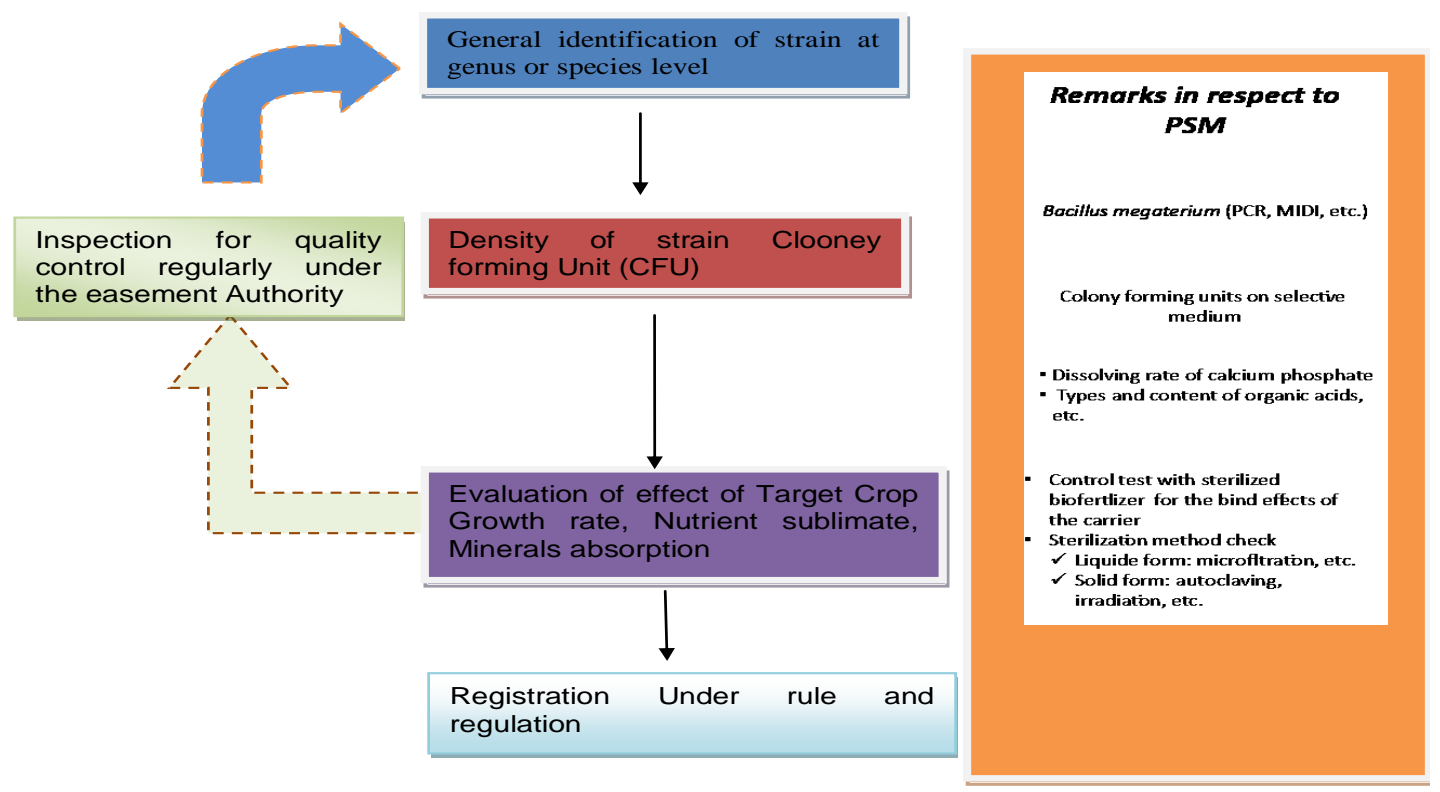
Fig.4 Different stage Research \& formulation /combinations of phosphate solubilizing bacteria
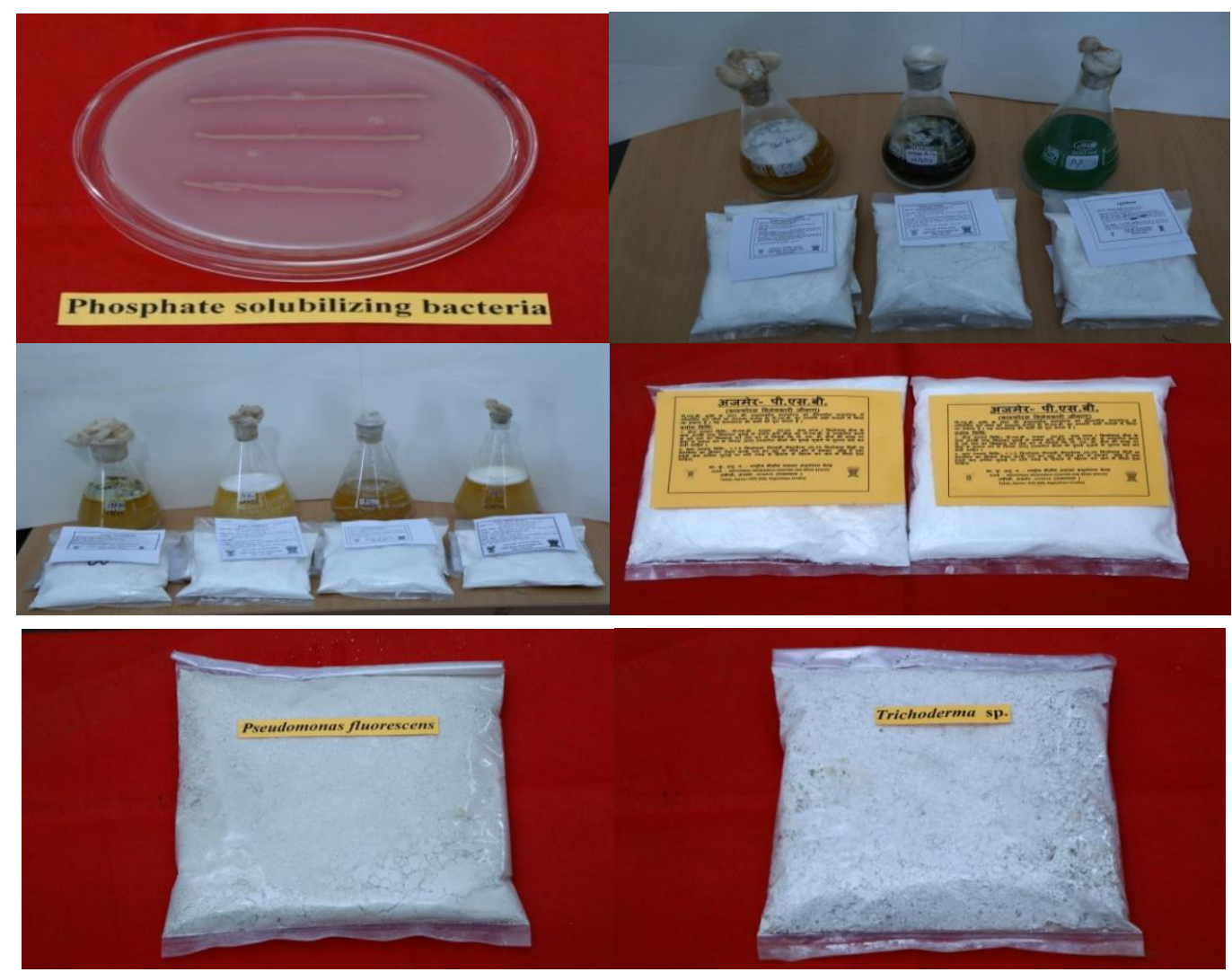

Biofertilizers have potential role in sustainable agriculture; these can be used along with chemical fertilizers to enhance the soil fertility and crop yield. In India, farmers' especially marginal farmers can get more profit from the same size of land by using biofertilizers instead of application of chemical fertilizers alone. However, most farmers are not aware of it; therefore, to popularize this technology (Borkar, S.G 2015). training should be provided to the farmers and this can be done through demonstration trials on the cultivator's fields. In this case, extension workers would play an important role. Moreover, more researches are needed to identify crop and location specific microbial strains with higher efficacy. The government should introduce strict law and policy against the quality of biofertilizers so that farmers can get benefits of this technology.

\section{References}

A. K. and Chandra K. 2012. National Seminar on Organic and Biological Inputs - New Innovations and Quality Control, Published by National Centre of Organic Farming, DAC, Ghaziabad, pp 19-24.

A. K. Yadav, A.K. Shukla, V.K. Verma and D. Gahlot. 1985. Biofertilizers and Organic Fertilizers in Fertilizer Control Order, National Seminar on "Organic and Biological Inputs -New Innovations and Quality Control, Published by National Centre of Organic Farming, DAC, Ghaziabad, pp 1-18.

Biofertilizer Manual by FNCA Biofertilizer 2006. Japan Atomic Industrial Forum (JAIF).

Borkar, S.G. Microbes as Biofertilizers and their Production Technology 
(2015).Woodhead Publish Yadav.

Chandra, K. 2011. Biofertilizer Newsletter 19 3-9.

Chang, CH, Yang SS. 2009.Thermotolerant phosphate solubilizing microbes for multifunctional bio-fertilizer preparation. Bioresearch Technology. 100(4):1648-58.

Drahas, D.J. Hemming, B.C. and Pherson, Mc. I 986. S. Biotechnology 4: 139-444.

Dudeja, S.S. and Khurana, A.L. 1989. The Pigeonpea-Rhizobium symbiosis a $\mathrm{s}$ affected by high root temperature: Effect of nodule formation J. Exn. Bot.: 40 (123) 469-472.

Duhan, J.S. and Yadav, D. S. 2001. A Review on Quality Control of Biofertilizer in India T.K. Ghosh, R.P. Singh, Regional Biofertilizer Development Centre Govt. of India, 18, Sirsa Road. Hisar - 125001 (Haryana).

Eaglesham, A.R.J. 1987. The use of antibiotic resistance for Rhizobium study "In Symbiotic nitrogen fixation study" Inc. New York: pp (185-20a).

Ghosh, T.K. 2000. Popularization of biofertilizer. In "Microbes in Integrated Nutrient Management". Academy of Agriculture Research and Educational Management. C.C.S. Haryana Agril. University, Hisar, India: pp. (61-67).

Ghosh, T.K. and Bhattacharyya, P. 1999. Isolation of temperature resistant strain of moong Rhizobium from Vidarbha soil and its antibiotic characterization. Indian Agric. 43 (1): 67 -70).

Gupta, AK. The Complete Technology Book on Biofertilizer and Organic Farming. National Institute of industrial research press India. 2004; 242-253.

Herrmann, L. and Lesueur, D. 2013. Challenges of formulation and quality of biofertilizers for successful inoculation. Applied Microbiology Biotechnology, 97: 8859-8873.

Khosro, M, and Yousef S. 2012. Bacterial bio-fertilizers for sustainable crop production: A review APRN Journal of Agricultural and Biological Science.; 7(5):237-308.

Lowe, D.J., Asbhy, G.A., 1995. Brune, M., Knights, H., Webb, M'.R. and Thornelay, R.N.F. In "Nitrogen Fixation Fundamental and Application" edited by I.A. Tikhonovich, N.A., Provorrv, V.I. Romanovnyl. London

Malus, E, Sas-Paszt, L. Ciesielska, J. 2012.Technologies for Beneficial Microorganisms Inocula Used as Biofertilizers. The Scientific World Journal, Article ID 491206.

Manashi, B. Srijita, P. Aditi, G. Choudhury, Pinaki, R. and Jahnavi, S. 2017. Biofertilizer as Prospective Input for Sustainable Agriculture in India. International Journal of Current Microbiology and Applied Sciences 6(11): 1177-1186. doi: https:// doi. org/ 10.20546 /ijcmas.2017.611.141.

Motsara, M. R., Bhattacharyya, P. and Srivastava. B. 1995. In "Biofertilizer Technology, Marketing and Usages", FDCO, New Delhi.

N.K. Arora. 2016. Bioformulation: for Sustainable Agriculture, DOI 10.1007/978-81-322-2779-3_1 Springer India.

NCOF Annual Report 2010-11. National Centre of Organic Farming, Department of Agriculture and Cooperation, Ghaziabad, UP, Published June 2011.

NCOF Annual Report 2011-12. National Centre of Organic Farming, Department of Agriculture and Cooperation, Ghaziabad, UP, Published June 2012.

Raja, N. 2013.Biopesticides and biofertilizers: ecofriendly sources for sustainable agriculture. Journal of Biofertilizer Biopesticides.; (3): 112-15.

Ritika, B, and Uptal, D. 2014.Bio-fertilizer a way towards organic agriculture: A Review. Academic Journals; 8(24): 
2332-42.

Sathya, A., Vijayabharathi, R., and Gopalakrishnan, S. 2017. Plant growthpromoting actinobacteria: a new strategy for enhancing sustainable production protection of grain legumes. 3 Biotech. 7:102. 10.1007/s13205-0170736-3.

Singh, T., and Ghosh, T.K. 2000. In "A Guide to Inoculant Technology" R.B.D.C., Hisar Publication.

Singh, T., Ghosh, T.K. Tyagi, M.K. and Duhan, J.S 1999. Fungicide rhizobial interaction at different methods of inoculation in green gram. Legume Res. 22(3): ts2-ts6.

Singh, T., Ghosh, T.K., Tyagi, M.L and Duhan, J.S 1999. Survival of rhizobia and level of contaminants in charcoal and lignite. Annals of Biology. 15(2): rss-rs8.

Somasegaran, P. and Hoben, J. 1994. Hand book for Rhizobia. Methods in legurne Rhizobium Technology for Research and Application. Springer, Verlag, New York.

Wollurn, A.G. 1987. Serological Technique for Brady Rhizobium and Rhizobium identification. In "Symbiotic nitrogen fixation study" Inc., New York.

Yadav, A.K. and Roy Chaudhary, S 1994. Exploitation of biofertilizer in ruorth eastern region. Edited by T. Singh NBDC, Ministry of Agriculture, Government of India. pp. 103.

Yadav, A.K. and Chandra K. 2014. Mass Production and Quality Control of Microbial Inoculants. Proc Indian Natn Sci Acad, 80 (2): 483-489.

Yadav, K.K. Sarka S. 2019. Biofertilizers, impact on soil fertility and crop productivity under sustainable agriculture. Environ. Ecol. 37, 89-93.

\section{How to cite this article:}

Mishra, B. K. and Barolia, S. K. 2020. Quality Assessment of Microbial Inoculants as Biofertilizer. Int.J.Curr.Microbiol.App.Sci. 9(10): 3715-3729.

doi: https://doi.org/10.20546/ijcmas.2020.910.428 